\title{
Helpful and Hindering Events in Internet-Delivered Cognitive Behavioural Treatment for Generalized Anxiety
}

\author{
John Burke \\ E-Mental Health Research Group, School of Psychology, Trinity College, Dublin and Research and \\ Innovation, SilverCloud Health, Dublin, Ireland
}

Derek Richards

E-Mental Health Research Group, School of Psychology, Trinity College, Dublin and Research and Innovation, SilverCloud Health, Dublin, Ireland

Ladislav Timulak

E-Mental Health Research Group School of Psychology, Trinity College, Dublin

\begin{abstract}
Background: Anxiety disorders are a highly prevalent cause of impairment globally with generalized anxiety disorder (GAD) sharing many features with other anxiety disorders. Aims: The present study investigated the helpful and hindering events and impacts for individuals with generalized anxiety who engaged with a supported 6-week online intervention based on cognitive behavioural therapy (iCBT). Method: Participants $(n=36)$ completed the Helpful and Hindering Aspects of Therapy (HAT) for each session. A descriptiveinterpretative framework was used to analyse the data. Results: Helpful events were identified by participants as CBT techniques including psychoeducation, monitoring, cognitive restructuring and relaxation, and found supporter interaction, mindfulness and reading personal stories helpful. The associated impacts were identified as support and validation; behavioural change/applying coping strategies; clarification, awareness, and insight; reassurance/relief; and self-efficacy/empowerment. Hindering events were identified as treatment content/form; and amount of work/technical issues, which led to impacts such as frustration/irritation; increased anxiety; and isolation. Conclusion: The implications of the results, potential future directions of research and limitations of the study are discussed.
\end{abstract}

Keywords: significant events in therapy, helpful and hindering events, internet-delivered interventions, generalized anxiety, descriptive-interpretative framework

Correspondence to Derek Richards, E-Mental Health Research Group, School of Psychology, Trinity College, Dublin, Ireland. E-mail: derek.richards@tcd.ie 


\section{Introduction}

Generalized anxiety disorder (GAD) is common, persistent and characterized by excessive worry about several events, including minor day-to-day matters in the past, present or future. Often, GAD presents comorbidly with mood disorders (Tyrer and Baldwin, 2006) and can cause significant distress and impairment in daily life for individuals (Judd et al., 1998). Lifetime prevalence rates are estimated at 6.2\% (Somers et al., 2006). It has been documented as one of the most difficult anxiety disorders to treat, yielding lower treatment response relative to other anxiety disorders (Jones, 2014).

\section{Treatment of $G A D$}

Reviews of GAD outcome research have indicated that pharmacotherapies and psychological treatments are effective (Tyrer and Baldwin, 2006). A comprehensive meta-analysis of psychological treatments for GAD concluding that CBT is the most empirically supported treatment available (Cuijpers et al., 2014). However, many cases of GAD go undiagnosed, especially in university settings where services are often overburdened with long waiting lists and lack of resources (Mowbray et al., 2006).

\section{Internet-based psychological interventions for GAD}

Internet-delivered interventions are accessible and offer greater access for those unlikely to seek traditional approaches to care due to stigmatization or preferences for self-reliance (Thomas et al., 2015). Such interventions can complement university services that are not resourced to offer more traditional costly and time-intensive services (Andersson and Cuijpers, 2009). Richards and colleagues (2015) meta-analysis evaluating internet-delivered interventions for GAD found large effect sizes comparable to those of face-to-face therapy for GAD across several outcome measures. Despite these results, research examining how internet-delivered interventions for GAD can integrate into routine practice is unclear (Batelaan et al., 2012). Furthermore, research has identified that there are largely differing responses to internetdelivered interventions across demographics, for certain personalities (Bendelin et al., 2011), and those with differing attitudes (Rochlen et al., 2004). Understanding the client experiences of iCBT is an integral aspect in supporting iCBT adoption into routine practice and evaluating significant events of therapy provides a means of doing this.

\section{Significant events research}

Significant events research (Elliott et al., 1985) represents the study of the important moments in therapy that elicit change for the client, either of a helpful or unhelpful (hindering) nature (Timulak, 2010). Evaluating the client's experience of therapy is often used to ascertain the processes whereby therapeutic methods are effective and inform service provision. Most of the research has been conducted through qualitative methods, mainly semi-structured interviews (Elliott, 2008).

Significant events research in internet-delivered treatments is limited and the therapeutic processes involved are relatively unknown. There has, however, been some qualitative research examining the psychological experience of users in iCBT treatments for depression (Bendelin 
et al., 2011; Gega et al., 2013). The Helpful/Hindering Aspects of Therapy (HAT) form is one questionnaire that gathers written data revealing client-identified significantly helpful and hindering events (Elliott et al., 2001). It has been used in previous studies that have assessed client-identified helpful and hindering events and their impacts (Gega et al., 2013; Richards and Timulak, 2012). This provides the opportunity to gain a qualitative insight into client experiences of iCBT.

The current study intended to gain an understanding of the helpful and hindering events and associated impacts of iCBT for GAD symptoms, specifically within a student population. The present study intended to contribute to significant events research in iCBT and provide guidance for developing future iCBT programmes for GAD.

\section{Methods}

\section{Design}

The study employed a qualitative design using a descriptive and interpretative framework (Elliott and Timulak, 2005). The qualitative data were obtained from a larger randomized controlled trial (RCT) evaluating iCBT for GAD in a university population (Richards et al., 2014, 2016).

\section{Participants}

Participants were recruited from an Irish University using an email advertisement for an internet-delivered course for anxiety called 'Calming Anxiety'. Further information on the trial design and its main outcomes is available (Richards et al., 2014, 2016). The primary outcome measure was the Generalized Anxiety Disorder 7-item scale (GAD-7; Spitzer et al., 2006). Those obtaining a score of 10 or above on GAD-7, equating to moderate to severe levels of anxiety according to normative values were included in the overall analysis (mean $=12.8$, $S D=2.68$ ). These scores correlate to a formal diagnosis of GAD as outlined in DSM-IV (Spitzer et al., 2006), but formal diagnostic assessment was not carried out on the present cohort.

\section{Sample size}

The original RCT recruited 137 students from an Irish-based university to engage with the 'Calming Anxiety' iCBT intervention. Participants were randomized into the immediate treatment group $(n=70)$ or a waiting list control group $(n=67)$. This participant group consisted of $69 \%$ female participants $(n=25)$ and $31 \%$ male $(n=11)$. Age ranged from 18 to 45 years $($ mean $=24.69, S D=7.37)$. A total number of 78 from a possible 216 HAT responses $(36 \%)$ were obtained from the 36 participants. Figure 1 shows the breakdown of HAT responses per session.

\section{Measure}

The HAT form (Llewelyn, 1988) was utilized to assess the most helpful and hindering events in therapy. Participants were asked to describe, in their own words, what they felt were the most significant events in each module for them. This event is anything identified by the participant 


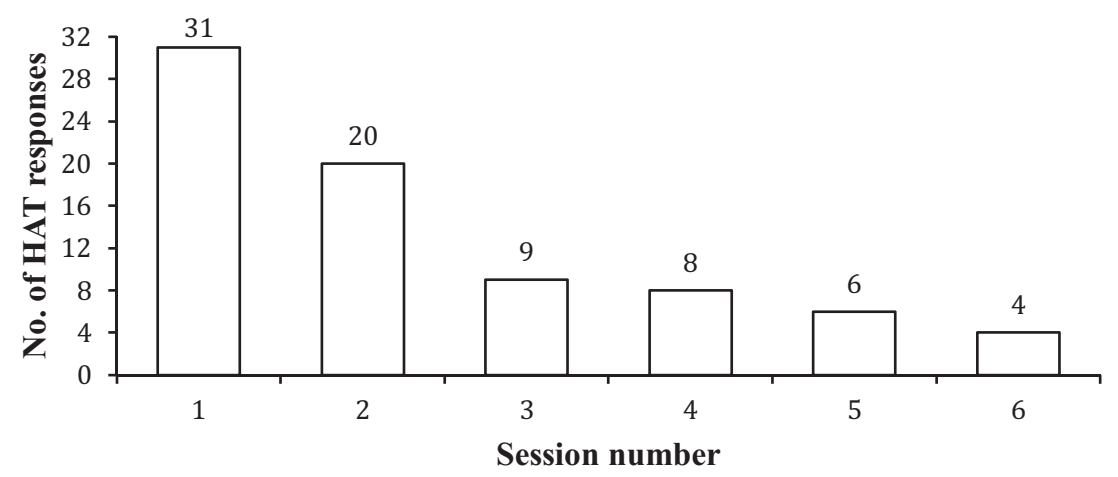

Figure 1. Column chart depicting number of HAT forms complete for each session

that they, the course or supporter said/did. The form also asks for a description of what made the event helpful or hindering for them, to elucidate their associated impacts.

\section{Procedure}

Participants were randomly allocated into one of two conditions - immediate access to the internet-delivered treatment intervention and delayed access to treatment using a waiting list control. The treatment was an iCBT program entitled 'Calming Anxiety' composed of six modules of CBT content for GAD consisting of cognitive, emotional and behaviour components (see Richards et al., 2014 for description of each module). In addition, participants received encouragement and specific feedback from their assigned supporter. Each supporter was a graduate psychology student qualified to Master's level or higher. Participants completed HAT measures from their second login to the platform where they were asked to reflect on the previous session and complete the questions.

\section{Data analysis}

Descriptive and interpretative (DI) qualitative analysis (Elliott and Timulak, 2005) was used to analyse the data collected to help understand the clients' perspectives on helpful and hindering events and impacts of the intervention. The first author received an Excel file containing the anonymized HAT data collected from participants of the main RCT. The process of analysis followed some distinct steps:

(1) The first author studied the data thoroughly, noting certain themes appearing regularly across participant responses. This process was repeated several times until the first author had a sufficient grasp of themes within the data.

(2) The data were divided into four domains: helpful events, helpful impacts, hindering events, hindering impacts. The clients' descriptions were considered about the event they described as well as the associated impact of the event. Richards and Timulak (2012) recommend this structure to organize the data, to determine what events are helpful/hindering as well as the impact of these events. 
Table 1. Instances for helpful and hindering events and helpful impacts for each category

\begin{tabular}{|c|c|c|c|}
\hline Helpful events & Pts & Helpful impacts & Pts \\
\hline Psychoeducation & $16 / 36$ & Support and Validation & $19 / 36$ \\
\hline Supporter Interaction & $15 / 36$ & $\begin{array}{l}\text { Applying Coping } \\
\text { strategies/Behavioural } \\
\text { Change }\end{array}$ & $19 / 36$ \\
\hline Monitoring & $10 / 36$ & $\begin{array}{l}\text { Clarification, Awareness and } \\
\text { Insight }\end{array}$ & $17 / 36$ \\
\hline Relaxation & $6 / 36$ & Reassurance/Relief & $12 / 36$ \\
\hline Mindfulness & $6 / 36$ & Self-Efficacy/Empowerment & $7 / 36$ \\
\hline Cognitive Restructuring & $4 / 36$ & & \\
\hline Reading Personal Stories & $3 / 36$ & & \\
\hline Other Skills & $3 / 36$ & & \\
\hline Hindering events & Pts & Hindering impacts & Pts \\
\hline Treatment Content/Form & $11 / 36$ & Frustration/Irritation & $7 / 36$ \\
\hline \multirow{2}{*}{$\begin{array}{l}\text { Amount of Work/Technical } \\
\text { Issues }\end{array}$} & $7 / 36$ & Increased Anxiety & $6 / 36$ \\
\hline & & Isolation & $4 / 36$ \\
\hline
\end{tabular}

Pts, number of participants whose responses exhibited data associated with specified event or impact, e.g. 16/36 means 16 out of 36 .

(3) Meaning units were identified, i.e. pieces of text that when placed outside of their context held a specific meaning.

(4) Through analysing these meaning units, reoccurring themes in the data were noted and general categories emerged. Each category was defined to reflect the content of data, ensuring each meaning unit was sufficiently represented by the category's definition to which it was assigned. This process was repeated several times to ensure accuracy.

(5) Further review of each category, category definitions along with the assigned meaning units was carried out by the second author, who has experience in DI analysis, to ensure accurate labelling and categorization of an 'event' or 'impact', and revisions made. The third author, with significant experience in conducting qualitative research, then reviewed the steps of the analysis and the outline of the findings. The changes suggested by the second and third author were then discussed and incorporated to the final analysis.

\section{Results}

DI analysis revealed a total of eight helpful events (Psychoeducation; Supporter Interaction; Monitoring; Relaxation; Mindfulness; Cognitive Restructuring; Reading Personal Stories; Other Skills) and five associated impacts (Support and Validation; Behavioural Change/Applying Coping Strategies; Clarification, Awareness and Insight; Reassurance/Relief; Self-Efficacy/Empowerment). Table 1 details the number of participants who experienced each helpful and hindering event and impact. Two hindering events were identified (Treatment Content/Form; Amount of Work/Technical Issues), with three associated impacts (Frustration/Irritation; Increased Anxiety; Isolation). The majority of the data was collected after sessions 1 and $2(n=51)$. Responses from sessions 3 to 6 were lower $(n=27)$. 
Therefore, the events and their associated impacts described pertain mainly to the initial sessions of the iCBT programme.

Each category was defined for helpful events and impacts (Table 2) and hindering events and impacts (Table 3). Each helpful and hindering event and impact is described in more detail below.

\section{Helpful events}

Supporter interaction ( $n=15$ ) encompasses any form of feedback, advice, encouragement or acknowledgement by the supporter in their personalized responses that were recognized as a helpful aspect of the course, e.g. My supporter did a really good summary of how I was feeling, it was good to see it written down from an outside perspective. Mindfulness $(n=6)$ techniques were another helpful event, e.g. The mindfulness tools were helpful in terms of how to relax. The Reading Personal Stories $(n=3)$ category relates to a specific component of the intervention where individuals describe their experience of anxiety making reference to common symptoms, thoughts, behaviours and feelings, e.g. I liked reading and relating to the personal stories. Other Skills $(n=3)$ were helpful events of learning unspecified skills to manage anxiety, e.g. Learning about the exercises for reducing my anxiety.

Participants reported learning four CBT techniques through their engagement with the programme. Psychoeducation $(n=19)$ involves learning a new piece of information relating to the prevalence of anxiety in the general population, what the potential causes of anxiety might be, how anxiety is perpetuated or how to reduce and manage anxiety, e.g. Reading about how common anxiety is. Monitoring $(n=10)$ refers to attending to one's actions, emotions, thoughts or physiological reactions, e.g. I am trying to track thoughts or events that elicit anxiety, and then (sic) trying to find the way to fix or avoid them. Relaxation $(n=6)$ involves learning methods for relaxation to reduce physiological tension, e.g. Relaxation tools available online - very useful for calming down at the end of a day. Cognitive Restructuring $(n=4)$ involves learning to refute cognitive distortions and replace them with healthier cognitions, e.g. Identifying hot thoughts will be worthwhile when I can master it, in the moment.

\section{Helpful impacts}

Five helpful impacts were identified. Nineteen participants described how they felt Supported or Validated through their engagement with the course. This feeling could occur because of supporter interaction, or clients' resonance with the course material, e.g. I feel like having someone there look over my progress generally has encouraged me to keep going with the programme. Nineteen participants reported that they Applied a New Skill or experienced Behavioural Change assisting them in managing their anxiety daily, e.g. I took the suggestion of the mindfulness exercise and am working on integrating this type of approach into everyday life. Seventeen participants reported developing an Awareness of the influences of anxiety, an Insight into recognizing their own anxiety or Clarification of aspects of anxiety that might previously have been ambiguous to them, e.g. It made me focus on my own situation and think about everything I had just read and how it related to me.

Twelve participants reported feeling Reassured, or gaining a sense of Relief, e.g. It was reassuring to see some events/feelings outlined in the cycle of anxiety that I thought were exclusive to me. Because of their engagement with the course, seven participants reported 
Table 2. Definition for each category of helpful event and impact

\begin{tabular}{|c|c|}
\hline Helpful event & Definition \\
\hline Psychoeducation & $\begin{array}{l}\text { Education on: how common anxiety is in the general population; the } \\
\text { causal factors in anxiety (i.e. Thoughts, Feelings Behaviour (TFB) } \\
\text { cycle; the mechanics whereby anxiety is perpetuated (i.e. } \\
\text { avoidance; poor sleep hygiene) and the ways that anxiety can be } \\
\text { reduced; learned through material in each session }\end{array}$ \\
\hline Supporter Interaction & $\begin{array}{l}\text { Receiving advice, encouragement, acknowledgement or general } \\
\text { feedback from the supporter. Sharing/disclosing information with } \\
\text { the supporter }\end{array}$ \\
\hline Monitoring & $\begin{array}{l}\text { Systematically attending to and evaluating one's current actions, } \\
\text { thoughts, emotions, or physiological reactions }\end{array}$ \\
\hline Relaxation & $\begin{array}{l}\text { Learning new habits based on relaxation principles that encourage } \\
\text { reduction of physiological tension or arousal }\end{array}$ \\
\hline Mindfulness & Using mindfulness techniques stated in the course \\
\hline Cognitive Restructuring & $\begin{array}{l}\text { Learning to refute cognitive distortions, and to replace these } \\
\text { cognitions with more helpful and healthier cognitions }\end{array}$ \\
\hline Reading Personal Stories & $\begin{array}{l}\text { Reading and relating to the personal stories described within the } \\
\text { course }\end{array}$ \\
\hline Other Skills & $\begin{array}{l}\text { The learning of non-specific, unspecified skills that do not fit into any } \\
\text { other category, that are helpful to manage anxiety }\end{array}$ \\
\hline Helpful impact & Definition \\
\hline Support and Validation & $\begin{array}{l}\text { Feeling their thoughts, feelings, fears and anxieties are accepted, } \\
\text { understood and validated through supporter interaction, or course } \\
\text { material engagement (i.e. by means of relating to personal stories) } \\
\text { Feeling that they are supported through their interaction with the } \\
\text { course rather than feeling alone as they might have had previously }\end{array}$ \\
\hline $\begin{array}{l}\text { Applying Coping } \\
\text { Strategies/Behavioural } \\
\text { change }\end{array}$ & $\begin{array}{l}\text { The application of new skills learned through participation in the } \\
\text { course (i.e. CBT techniques; mindfulness) that they have continued } \\
\text { to practise outside of the course requirements that have been helpful } \\
\text { in managing or controlling their anxiety }\end{array}$ \\
\hline $\begin{array}{l}\text { Clarification, Awareness } \\
\text { and Insight }\end{array}$ & $\begin{array}{l}\text { Developing awareness of how certain life events and daily life } \\
\text { experiences can influence anxiety; an insight into the recognition of } \\
\text { their own anxiety, realizing the impact of their anxiety on their life } \\
\text { and what they can do to control the anxiety they experience } \\
\text { Clarifying certain aspects of the contributory and perpetuating } \\
\text { factors of anxiety that participants may have previously held } \\
\text { misconceptions about }\end{array}$ \\
\hline Reassurance/Relief & $\begin{array}{l}\text { Gaining reassurance from supporter or course material. Feeling relief } \\
\text { through engagement with the course material and/or supporter } \\
\text { feedback }\end{array}$ \\
\hline $\begin{array}{l}\text { Self- } \\
\text { Efficacy/Empowerment }\end{array}$ & $\begin{array}{l}\text { Feeling 'in control' of their anxiety, feeling that they have the ability } \\
\text { to manage their own issues through engagement with the } \\
\text { programme. Identifying their own role in tackling their anxiety and } \\
\text { moving towards taking control of it themselves }\end{array}$ \\
\hline
\end{tabular}


Table 3. Definition for each category of hindering event and impact

\begin{tabular}{ll}
\hline Event & Definition \\
\hline $\begin{array}{l}\text { Treatment } \\
\text { content/form }\end{array}$ & $\begin{array}{c}\text { Comments made about the material encountered within the course } \\
\text { (i.e. personal stories) or relating to the computer-based, short-term } \\
\text { form of treatment. For example, comments made about the } \\
\text { ineffectiveness or irrelevance of material } \\
\text { Any issue related to course structure, the layout and/or administration } \\
\text { of the course, any technical difficulties encountered, or issues with } \\
\text { time commitment required for engagement with the course }\end{array}$ \\
\hline Definition \\
\hline $\begin{array}{l}\text { Events experienced as a result of engagement with the course causing } \\
\text { frustration and/or irritation for participants } \\
\text { Clients experiencing an increase in their anxiety as a result of } \\
\text { engaging with the course } \\
\text { Events making participants feel as though they are unsupported } \\
\text { throughout their participation in the course, and feeling isolated as } \\
\text { though they are experiencing symptoms that are not commonly } \\
\text { experienced by others }\end{array}$ \\
Isolation
\end{tabular}

instances of feeling 'in control' of their anxiety through Self-Efficacy/Empowerment and having the ability to manage the issues they are experiencing because of their anxiety, e.g. I feel $a$ little less out of control.

\section{Hindering events}

Eleven participants in this category alluded to unhelpful course material (Content/Form) such as the personal stories not resonating with them, or to the online, short-term nature of the programme as unsuitable for them, e.g. I just find it hard to start certain activities because the examples available, though still helpful, are not really like my problems or anxiety. Seven participants noted issues with the course structure, administration or the time commitment required to engage (Amount of Work/Technical Issues), e.g. Some of the content was a little bit long.

\section{Hindering impacts}

Three hindering impacts were identified. This first category captured instances of Frustration and Irritation seven participants felt while completing the course, e.g. Ifound much of the advice impossible to achieve with a student lifestyle, hours at college and a house full of students. Six participants reported feeling an increased level of Anxiety because of their participation, for example due to monitoring and recording their anxiety or technical administration, e.g. Anxiety triggered whenever I saw I had a [programme name] email. Four participants reported feeling Isolated through their engagement with the programme, e.g. The examples available, are not really like my problems or anxiety. It kind of makes me feel a bit more alone as no one seems to feel the same things I do. 


\section{Discussion}

The present study set out to gain an understanding of how students enrolled in a university course experience an iCBT intervention for GAD symptoms. Specifically, it aimed to identify the significantly helpful and hindering events of the course and their potential impacts. Participants found certain aspects of the course particularly helpful. CBT techniques such as Psychoeducation, Monitoring, Relaxation and Cognitive Restructuring were helpful for some participants. Mindfulness and Reading Personal Stories and Other Skills not specifically named were helpful, while the Supporter Interaction also played a significant role for some participants.

Several participants began to Apply Coping Strategies or experience Behavioural Change in their daily lives because of their engagement with the programme. Feeling Supported and Validated cultivated a feeling of Self-Efficacy/Empowerment for some participants. Developing Clarification on, and Awareness or Insight into how their own life is affected by anxiety, were helpful impacts. The internet-delivered course evoked a feeling of Reassurance/Relief among participants, who previously felt their anxiety was all consuming.

Some hindering aspects were also identified. The Treatment Content/Form left some people feeling Frustrated or Irritated by the Amount of Work required and Technical Issues relating to layout or administration. Some participants found the online platform too like their working environment. Those who did not feel supported and validated instead felt Isolated and some were left with an increased level of Anxiety.

The presence of Applying Coping Strategies/Behavioural Change as a prominent clientidentified impact in the data indicates that 'Calming Anxiety' was successful in equipping some participants with strategies to manage their anxiety. This is an important facet of treatment, as these individuals may now have some resources to manage their anxiety and these may offset the need for more intensive treatment.

Some participants reported that the relational element developed through personalized feedback allowed their anxiety to be validated; evidence suggests that validation is important for improvement when treating any psychological disorder (Linehan, 1997). The responses of some participants suggest that the supporter was an integral component of the intervention for their outcomes. Supported internet-delivered interventions generally yield better outcomes (Andersson and Cuijpers, 2009; Richards and Richardson, 2012). However, over half of the participants did not cite the supporter in their responses as either a helpful or hindering aspect. The issues within research concerning the involvement of a supporter in iCBT were mentioned previously (Titov et al., 2013) and the present results serve to pose more questions rather than provide answers in this debate.

It could be the case that individuals who did not highlight the supporter interaction in their responses were assigned a supporter less skilled in relating to participants through their feedback. Alternatively, it could be suggested that two pathways to treatment success exist one relying on skills and strategies and the other on the interpersonal aspects of the programme and the supporter (Richards et al., 2013; Richards et al., 2017).

A sense of empowerment was experienced by seven participants and such an outcome is a welcome therapeutic benefit from the course. Some individuals, however, may have had a greater sense of self-efficacy prior to engagement, but all may have valued gaining knowledge on coping strategies that they could implement themselves and enhance self-management 
(Dwyer et al., 2011). This may be facilitative of students given the preference to foster a sense of autonomy (Gulliver et al., 2012).

Awareness and insight are commonly reported categories in significant events research (Timulak, 2007). Gaining an insight into these detrimental effects of anxiety on one's behavioural and cognitive functioning, and how these effects could be managed revealed itself as a powerful impact within the present data. However, for both internet-delivered and traditional forms of therapy it is argued that the therapist (or supporter in this case) is required to facilitate the client in reaching the deepest potential of the significant insight resulting in the most significant change (Elliott, 1985). The issue of sufficient therapist presence in these moments is an area ripe for future research.

It may be the case that these significant insights are not navigated to their full potential. This is not necessarily a criticism that can only be levelled at iCBT, it can also be the case in other delivery mediums. To add to this dynamic, it may be the case that these differences are unrelated to the administration of the intervention. Instead, each client's personal and interpersonal characteristics colour their experiences of the supporter and report different types of events in keeping with these differences.

The delivery and presentation of the material in earlier iCBT interventions was identified as a hindering event in a significant number of client experience evaluation studies (Ritterband et al., 2003). The present results indicate less prominent hindrances of engaging with this intervention, portraying the advancements in technology and expertise in internetdelivered interventions markedly improving the presentation and delivery. However, hindrances were identified relating to the content, general administration and technical features. The consideration of participants' hindering experiences and their impact can only advance our knowledge of how to further develop interventions to promote and optimize engagement.

\section{Implications for clinical practice and future research}

The present findings contribute to the growing list of studies evaluating client experiences of internet-delivered interventions. To the researchers' knowledge, it is the first qualitative study of participant-identified significant events, specifically iCBT for GAD symptoms.

Whether the involvement of a supporter is related to self-efficacy of an individual, and what characteristics are salient for participants placing a greater reliance on the supporter's role are two important avenues of research. Further research is welcomed on the function of the supporter: can support facilitate participants to gain knowledge, insight and develop strategies, or does it result in an over-reliance, leading to little or no learning of coping strategies? Given the importance of developing insight for therapeutic change, future research might be useful to understand the level of insight iCBT and internet-delivered interventions in general can bring and comprehend the impact of differing levels of support in this process. Furthermore, determining whether the supporter is capable of sufficiently navigating developments in insight for participants would refine the role of the supporter in internet-delivered interventions. There is also a case for evaluating supporter feedback to determine whether outcomes depend on the supporter they were assigned to determine if the intervention impacts client experiences above personal and interpersonal differences.

Delineating these complex interactions with internet-delivered interventions is important for continuous advancement in internet-delivered interventions research and bringing parity between the knowledge and research on internet-delivered interventions and traditional 
methods of therapy. This challenge will require innovative methods to capture the experience of users and therapists.

\section{Limitations}

It is generally accepted that qualitative research can hold significance with lower numbers of participants and responses. However, the high rates of attrition between the total number of participants and the number of participants who completed HAT forms could be a potential limitation. Most events and impacts described were observed within the first two iCBT sessions. The participants had not yet navigated through modules describing graded exposure, challenging negative thoughts and summary modules. Therefore, there is the potential that some events occurred in the latter sessions that were not captured in the present analysis. In addition, participants may have described the experiences of the first two sessions differently having completed the entire programme. For example, technical issues and the associated frustration may not have been as prominent as participants increased their computer competence throughout their use of the programme. However, the present data do not provide the opportunity to examine the participant experiences of latter modules. Furthermore, it was not possible to capture the experiences of those who dropped out of the intervention, which would be useful to address potential shortcomings of iCBT in meeting user needs and expectations.

The data was gathered from a university student sample. This was a heterogeneous sample capturing a range of demographics. This sample is potentially more computer-literate and has a higher level of education in comparison with the general population.

The results of the primary study outcomes outlined how participants presented with GAD symptoms as opposed to GAD disorder (Richards et al., 2016). This discrepancy may have been due to the use of the GAD-7 alone to establish GAD in the sample. This can be considered a limitation, as it cannot be assumed that a moderate/severe score on the GAD-7 equates directly to a formal GAD diagnosis. Despite this, client experiences were being evaluated rather than outcomes in the present paper, and GAD-7 scores represent a sufficient measure of participant's self-reported anxiety.

The authors used auditing to ensure the quality and accuracy of analysis but as is the case with all qualitative research, there is a subjective component to the analysis that may have influenced the interpretation of the data.

\section{Conclusion}

Analysing client experiences has demonstrated that iCBT (Calming Anxiety) contains helpful elements that can have relevant impacts. Many participants reported a greater insight into their anxiety and learned skills they could apply in their daily lives. Through the application of these skills, they gained a sense of empowerment and self-efficacy, motivating them to manage their anxiety. The programme left some participants feeling supported and validated, much of which was due to supporter interaction throughout the course. As previously noted, some aspects of the treatment content and form caused an increase in anxiety. The suitability, or unsuitability of the course material for a small percentage of participants presents an issue for developers, clinicians and researchers alike that needs to be addressed in the development of future iCBT interventions to reduce the instance of hindering, negative impacts because of engaging with the programme. Beginning to understand the more complex processes involved 
in internet-delivered interventions is an important avenue for research and should be prioritized if internet-delivered interventions are to be widely implemented into routine care, namely in relation to therapeutic insight and the role of the supporter for participants.

The present study makes a much-needed contribution to the field of research evaluating client experiences within internet-delivered interventions. More specifically, it provides a qualitative perspective on the use of iCBT for GAD symptoms. Future research should continue to support the utilization of iCBT for GAD as a low-intensity intervention within routine practice of university psychological services to manage the increasing issue of untreated anxiety in the student population.

\section{Acknowledgements}

The authors would like to acknowledge the authors of the primary study for the provision of secondary data evaluated in this study (Richards et al., 2014, 2016).

Thanks to all of the people who participated in the study. Thanks also to the student counselling service for hosting the study.

Ethical statements: The authors have abided by the Ethical Principles of Psychologists and Code of Conduct as set out by the APA. Ethical approval for the original study was obtained from the School of Psychology Research Ethics Committee, Trinity College Dublin, Ireland (22 November 2013). The authors adhere to both research ethics and Trinity College Dublin policy on good research practice. Approval for examination of the secondary data was provided by the same committee on 2 December 2015.

Conflicts of interest: Mr John Burke, Dr Derek Richards and Dr Ladislav Timulak declare no conflicts of interest.

Financial support: This trial was jointly funded from monies and resources provided by SilverCloud Health Ltd and Trinity College Dublin student counselling service.

\section{References}

Andersson, G. and Cuijpers, P. (2009). Internet-based and other computerized psychological treatments for adult depression: a meta-analysis. Cognitive Behaviour Therapy, 38, 196-205. doi: 10.1080/16506070903318960

Batelaan, N. M., Smit, J. H., Cuijpers, P., van Marwijk, H. W., Terluin, B. and van Balkom, A. J. (2012). Prevention of anxiety disorders in primary care: a feasibility study. BMC Psychiatry, 12, 1. doi: 10.1186/1471-244X-12-206

Bendelin, N., Hesser, H., Dahl, J., Carlbring, P., Nelson, K. Z. and Andersson, G. (2011). Experiences of guided internet-based cognitive-behavioural treatment for depression: a qualitative study. $B M C$ Psychiatry, 11, 1. doi: 10.1186/1471-244X-11-107

Cuijpers, P., Sijbrandij, M., Koole, S., Huibers, M., Berking, M. and Andersson, G. (2014). Psychological treatment of generalized anxiety disorder: a meta-analysis. Clinical Psychology Review, 34, 130-140. doi: 10.1016/j.cpr.2014.01.002

Dwyer, L. A., Hornsey, M. J., Smith, L. G., Oei, T. P. and Dingle, G. A. (2011). Participant autonomy in cognitive behavioral group therapy: an integration of self-determination and cognitive behavioral theories. Journal of Social and Clinical Psychology, 30, 24. doi: 10.1521/jscp.2011.30.1.24 
Elliott, R. (1985). Helpful and nonhelpful events in brief counseling interviews: an empirical taxonomy. Journal of Counseling Psychology, 32, 307-322. doi: 10.1037/0022-0167.32.3.307

Elliott, R. (2008). Research on client experiences of therapy: introduction to the special section. Psychotherapy Research, 18, 239-242. doi: 10.1080/10503300802074513

Elliott, R., James, E., Reimschuessel, C., Cislo, D. and Sack, N. (1985). Significant events and the analysis of immediate therapeutic impacts. Psychotherapy: Theory, Research, Practice, Training, 22, 620. doi: $10.1037 / \mathrm{h} 0085548$

Elliott, R., Slatick, E. and Urman, M. (2001). Qualitative change process research on psychotherapy: alternative strategies. Psychological Test and Assessment Modeling, 43, 69. doi: 10.1002/9781119973249.ch6

Elliott, R. and Timulak, L. (2005). Descriptive and interpretative approaches to qualitative research. In J. Miles and P. Gilbert (eds), A Handbook of Research Methods in Clinical and Health Psychology (pp. 147-160). Oxford: Oxford University Press. Retrieved from: http://nideffer.net/classes/GCT_ RPI_S14/readings/interpretive.pdf

Gega, L., Smith, J. and Reynolds, S. (2013). Cognitive behaviour therapy (CBT) for depression by computer vs. therapist: patient experiences and therapeutic processes. Psychotherapy Research, 23, 218-231. doi: 10.1080/10503307.2013.766941

Gulliver, A., Griffiths, K. M., Christensen, H. and Brewer, J. L. (2012). A systematic review of helpseeking interventions for depression, anxiety and general psychological distress. BMC Psychiatry, 12, 1. doi: $10.1186 / 1471-244 X-12-81$

Jones, S. L. (2014). An efficacy trial of therapist-assisted internet-delivered cognitive-behaviour therapy for older adults with generalized anxiety. Unpublished doctoral dissertation, University of Regina, Canada. Retrieved from: http://ourspace.uregina.ca/handle/10294/5818

Judd, L., Kessler, R., Paulus, M., Zeller, P., Wittchen, H. and Kunovac, J. (1998). Comorbidity as a fundamental feature of generalized anxiety disorders: results from the National Comorbidity Study (NCS). Acta Psychiatrica Scandinavica Supplement, 393, 6-11. doi: 10.1111/j.16000447.1998.tb05960.x

Linehan, M. M. (1997). Validation and Psychotherapy. In A. C. Bohart and L. S. Greenberg (eds), Empathy Reconsidered: New Directions in Psychotherapy (pp. 353-392). doi: 10.1037/10226-016

Llewelyn, S. P. (1988). Psychological therapy as viewed by clients and therapists. British Journal of Clinical Psychology, 27, 223-237.

Mowbray, C. T., Mandiberg, J. M., Stein, C. H., Kopels, S., Curlin, C., Megivern, D., Strauss, S., Collins, K. and Lett, R. (2006). Campus mental health services: recommendations for change. American Journal of Orthopsychiatry, 76, 226-237. doi: 10.1037/0002-9432.76.2.226

Richards, D., Dowling, M., O’Brien, E., Viganò, N. and Timulak, L. (2017). Significant events in an internet-delivered (Space from Depression) intervention for depression. Counselling and Psychotherapy Research. doi: 10.1002/capr.12142

Richards, D. and Richardson, T. (2012). Computer-based psychological treatments for depression: a systematic review and meta-analysis. Clinical Psychology Review, 332, 329-342. doi: 10.1016/j.cpr.2012.02.004

Richards, D., Richardson, T., Timulak, L. and McElvaney, J. (2015). The efficacy of internetdelivered treatment for generalized anxiety disorder: a systematic review and meta-analysis. Internet Interventions, 2, 272-282. doi: 10.1016/j.invent.2015.07.003

Richards, D. and Timulak, L. (2012). Satisfaction with therapist-delivered vs. self-administered online cognitive behavioural treatments for depression symptoms in college students. British Journal of Guidance and Counselling, 41, 193-207. doi: 10.1080/03069885.2012.726347

Richards, D., Timulak, L., Doherty, G., Sharry, J., McLoughlin, O., Rashleigh, C., Colla, A. and Joyce, C. (2014). Low-intensity internet-delivered treatment for generalized anxiety symptoms in routine care: protocol for a randomized controlled trial. Trials, 15. doi: 10.1186/1745-6215-15-145 
Richards, D., Timulak, L. and Hevey, D. (2013). A comparison of two online cognitive-behavioural interventions for symptoms of depression in a student population: the role of therapist responsiveness. Counselling and Psychotherapy Research, 13, 184-193. doi: 10.1080/14733145.2012.733715

Richards, D., Timulak, L., Rashleigh, C., McLoughlin, O., Colla, A., Joyce, C., Doherty, G., Sharry, J., Duffy, D. and Anderson-Gibbons, M. (2016). Effectiveness of an internet-delivered intervention for generalized anxiety disorder in routine care: a randomised controlled trial in a student population. Internet Interventions, 1-9. doi: 10.1016/j.invent.2016.10.003

Ritterband, L. M., Gonder-Frederick, L. A., Cox, D. J., Clifton, A. D., West, R. W. and Borowitz, S. M. (2003). Internet interventions: in review, in use, and into the future. Professional Psychology: Research and Practice, 34, 527. doi: 10.1037/0735-7028.34.5.527

Rochlen, A. B., Zack, J. S. and Speyer, C. (2004). Online therapy: review of relevant definitions, debates, and current empirical support. Journal of Clinical Psychology, 60, 269-283. doi: 10.1002/jclp. 10263

Spitzer, R. L., Kroenke, K., Williams, J. B. and Löwe, B. (2006). A brief measure for assessing generalized anxiety disorder: the GAD-7. Archives of Internal Medicine, 166, 1092-1097. doi: 10.1001/archinte.166.10.1092

Somers, J. M., Goldner, E. M., Waraich, P. and Hsu, L. (2006). Prevalence and incidence studies of anxiety disorders: a systematic review of the literature. Canadian Journal of Psychiatry, 51, 100-113. Retrieved from: http://ww1.cpa-apc.org:8080/Publications/Archives/CJP/2006/february/ sommers-RP.asp

Thomas, N., McLeod, B., Jones, N. and Abbott, J. A. (2015). Developing internet interventions to target the individual impact of stigma in health conditions. Internet Interventions, 2, 351-358. doi: 10.1016/j.invent.2015.01.003

Timulak, L. (2007). Identifying core categories of client-identified impact of helpful events in psychotherapy: a qualitative meta-analysis. Psychotherapy Research, 17, 305-314. doi: 10.1080/10503300600608116

Timulak, L. (2010). Significant events in psychotherapy: an update of research findings. Psychology and Psychotherapy: Theory, Research and Practice, 83, 421-447. doi: 10.1348/147608310X499404

Titov, N., Dear, B. F., Johnston, L., Lorian, C., Zou, J., Wootton, B., Spence, J., McEvoy, P. M. and Rapee, R. M. (2013). Improving adherence and clinical outcomes in self-guided internet treatment for anxiety and depression: randomised controlled trial. PLoS One, 8, e62873. doi: 10.1371/journal.pone.0062873

Tyrer, P. and Baldwin, D. (2006). Generalised anxiety disorder. The Lancet, 368, 2156-2166. doi: 10.1016/S0140-6736(06)69865-6 